\title{
Eläinten käyttäytymisen tutkiminen videoaineistoista otantamenetelmällä
}

\author{
Lauri Jauhiainen ${ }^{1)}$ ja Hannu T. Korhonen ${ }^{2)}$ \\ ${ }^{1)}$ MTT, Tutkimuspalvelut, Tietopalvelut,31600Jokioinen, lauri.jauhiainen@mtt.fi \\ ${ }^{2)}$ MTT, Kotieläintuotannontutkimus, Turkiseläimet,69100Kannus, hannu.t.korhonen@mtt.fi
}

\section{Johdanto}

Eläinten hyvinvointitutkimuksessa käyttäytymiseen liittyvät muuttujat havainnoidaan usein videotallenteista otantamenetelmällä (instantaneous sampling method/scan sampling) (Martin ja Bateson 1986; Lehner 1996). Käytetty menetelmä perustuu systemaattiseen otantaan, jossa tutkittavat aikapisteet valitaan tietyn aikaeron välein. Kussakin valitussa aikapisteessä tallennetaan 0/1-havainto sen mukaan, suorittaako eläin jotain kiinnostavaa toimintoa vai ei. Menetelmä on sovelias havaitsemaan, montako prosenttia ajasta eläin käyttää kuhunkin toimintoon, mutta menetelmä ei sovellu mittaamaan toimintojen kestoja tai lukumääriä (Altmann 1974). Useita kymmeniä erilaisia toimintoja voidaan löytää videoaineistoista ja siksi videoaineiston purkaminen on työläs vaihe, varsinkin jos otannassa käytetty aikaero on lyhyt. Autokorrelaatio voidaan helposti havaita videoaineistoista (Jauhiainen ja Korhonen 2003) eli tietyllä hetkellä tehty havainto riippuu saman eläimen aikaisemmista havainnoista. Diggle (1990) on kuvannut ilmiön esiintymistä biotieteissä ja lisäksi hän on osoittanut variogrammin olevan käyttökelpoinen työkalu autokorrelaatiota mallitettaessa (Diggle ym. 1994).

Käytetty otantatiheys vaihtelee paljon tutkimuksesta toiseen ollen keskimäärin 3 minuuttia, mutta jopa 15 sekunnin (Andersen ym. 1999) ja 15 minuutin (Lay ym. 1999) otantatiheyksiä on löydettävissä kirjallisuudesta. Engel (1996) esitti graafisen menetelmän, jonka avulla voidaan määrittää käyttökelpoinen otantatiheys. Engelin menetelmä perustuu autokorrelaatioon, mutta autokorrelaatiofunktiota hän ei kuitenkaan mallittanut. Koska optimaalinen otantatiheys on sidoksissa tutkittavan käyttäytymistoiminnon keskimääräiseen kestoon Bernstein (1991) suositteli käyttämään tiheyttä, jossa aikapisteiden välinen ero on suurempi kuin toiminnon keskimääräinen kesto.

Käyttäytymistutkimuksissa ollaan usein kiinnostuneita siitä, kuinka käyttäytyminen muuttuu kokeen kuluessa ja onko muutos samanlainen eri käsittelyryhmissä (Lehner 1996). Näin ollen videonauhoituksia tehdään eri päivinä tai eri kuukausina ja videotallenteiden purkaminen muuttuu entistä työläämmäksi ja kalliimmaksi työvaiheeksi. Näin ollen kustannustehokkaan otantatiheyden määrittäminen on tärkeää ja tämän tutkimuksen tavoitteeksi asetettiin i) mallittaa autokorrelaatiofunktio käyttäen variogrammia sekä ii) määrittää optimaalinen otantatitiheys sinikettujen (Alopex lagopus) käyttäytymistutkimuksia varten.

\section{Aineisto ja menetelmät}

\section{Eläinaines ja tuotanto-olosuhteet}

Tutkimus käytti aineistonaan koetta, mikä oli alkujaan suunniteltu vertailemaan erilaisia häkkityyppejä. Koe suoritettiin vuonna 1997 Turkistalouden tutkimusasemalla Kannuksessa (MTT). Kokeessa oli 40 nuorta sinikettua. Eläimet olivat yksilöhäkeissä perinteisessä varjotalossa. Tutkimuksen ovat kuvanneet tarkemmin Korhonen ym. (2001).

\section{Videokuvaukset}

Eläinten käyttäytyminen kuvattiin viitenä vuorokauden jaksona ja kuvaus toistettiin neljänä peräkkäisenä kuukautena (elokuu-marraskuu). Havainnot tehtiin otantamenetelmällä yhden minuutin välein. Yli 30 erilaista käyttäytymistoimintoa löydettiin, joista neljää tarkastellaan tässä tutkimuksessa: lepääminen, stereotypiat, liikkuminen ja itsensä raapiminen.

\section{Autokorrelaatio}

Semivariogrammi (Kaava 1) laskettiin kuvaamaan havaintojen aikariippuvuutta.

$$
\gamma(h)=\frac{1}{2 N(h)} \sum_{i=1}^{N(h)}\{y(x+h)-y(x)\}^{2}
$$


missä $\mathrm{y}(\mathrm{x}+\mathrm{h})$ ja $\mathrm{y}(\mathrm{x})$ ovat 0/1-muuttujan havaittuja arvoja ajanhetkiltä $\mathrm{x}$ ja $\mathrm{x}+\mathrm{h}$. $\mathrm{N}(\mathrm{h})$ on niiden havaintoparien määrä, joissa havaintojen aikaero on h minuuttia. Variogrammi, $\gamma(h)$, mallitettiin käyttäen tavallista eksponentiaalista mallia (Kaava 2) sekä kaksi komponenttia sisältävää eksponentiaalista mallia (Kaava 3).

$$
\begin{aligned}
& \gamma(h)=c\left\{1-\exp \left(-\frac{h}{r}\right)\right\} \\
& \gamma(h)=c_{\text {short }}\left\{1-\exp \left(-\frac{h}{r_{\text {short }}}\right)\right\}+c_{\text {long }}\left\{1-\exp \left(-\frac{h}{r_{\text {long }}}\right)\right\}
\end{aligned}
$$

missä $\mathrm{r}, \mathrm{r}_{\text {short }} \mathrm{ja} \mathrm{r}_{\text {long }}$ ovat komponentin vaikutusaikoja (range) kun taas $\mathrm{c}, \mathrm{c}_{\text {short }} \mathrm{ja} \mathrm{c}_{\text {long }}$ komponenttien sill-tasoja. Vaikutusaika (range) on aikaero, jolloin autokorrelaatio häviää ja sill on toisistaan riippumattomien havaintojen varianssi (=variogrammin maksimiarvo). Variogrammi laskettiin ja mallitettiin käyttäen VarioWin- (Pannatier 1996) ja SAS/NLIN -ohjelmaa (SAS 1999).

\section{Optimaalinen otantatiheys}

Alkuperäinen aineisto kerättiin yhden minuutin välein viitenä vuorokauden jaksona kuukausittain. Tätä harvemmat otannat sekä lyhyemmät kuvausjaksot saatiin poistamalla alkuperäisestä aineistosta osa havainnoista.

Koeasetelma oli satunnaistettujen täydellisten lohkojen koeasetelma, missä pentue toimi lohkotekijänä. Kultakin eläimeltä havainnot kerättiin neljänä kuukautena ja tilastollisessa mallissa kuukautta käsiteltiin toistotekijänä. Samasta eläimestä tehtyjen toistomittauksien korrelaatio huomioitiin ja toistomittausten kovarianssi-varianssimatriisi valittiin käyttäen Akaiken informaatiokriteeriä ja uskottavuusosamäärätestiä (Wolfinger 1996). Käytetyn mallin yksityiskohtaisemman kuvauksen ovat tehneet mm. Gumperetz ja Browne (1993). Analysoinnin yhteydessä laskettiin kolme erotusta: (1) kahden käsittelyn keskimääräinen ero, (2) kahden käsittelyn keskimääräinen ero elokuussa ja (3) kuinka kahden käsittelyn ero elokuussa eroaa vastaavasta erosta syyskuussa. Eroille laskettiin keskivirhe ja kolmea keskivirhettä merkitään jatkossa merkinnöin $\mathrm{SED}_{1}, \mathrm{SED}_{2}$ ja $\mathrm{SED}_{3}$. Kontrollimenetelmäksi valittiin menetelmä, jossa havainnointi tehdään kahden minuutin välein ja eläimiä kuvataan 24 tuntia kuukaudessa. Tilastollinen malli sovitettiin SAS/MIXED-ohjelmistolla (SAS 1999).

\section{Tulokset ja tulosten tarkastelu}

\section{Autokorrelaatio}

Koska useiden käyttäytymistoimintojen yleisyys riippuu vuorokauden ajasta (Korhonen ym. 2001), variogrammi laskettiin ja mallitettiin erikseen kolmena kahdeksan tunnin jaksona (kello 00:00-8:00, 8:00-16:00 ja 16:00-24:00). Mallin ja aineiston yhteensopivuuden tarkastelu paljasti, että tavallinen eksponentiaalinen malli (Kaava 2) sopi aineistoon huomattavasti heikommin kuin kaksi komponenttia sisältävä eksponentiaalinen malli (Kaava 3). Tämä toistui kaikissa tutkituissa käyttäytymistoiminnoissa ja kaikkina vuorokaudenaikoina.

Kaikissa toiminnoissa komponentit voitiin nimetä lyhyen ja pitkän vaikutuksen komponenteiksi. Lyhyen komponentin kesto oli vain muutama minuutti, kun taas pitkän komponentin kesto oli lepäämisessä yli tunti ja muissa toiminnoissa 20-40 minuuttia (Taulukko 1). Vuorokaudenajalla ei ollut juurikaan merkitystä vaikutusten kestoon. Sill-parametrin arvo oli lyhyessä komponentissa suurempi kuin pitkässä komponentissa (Taulukko 1) lukuun ottamatta lepäämistä. Tämä kaikki tarkoittaa käytännössä sitä, että variogrammi nousee ensimmäisten minuuttien aikana nopeasti ja iso osa autokorrelaatiosta katoaa otantatiheyden ollessa 4-5 minuuttia tai enemmän.

Siniketuilla aktiviteeteistä yli puolet on kestoltaan alle 2 minuuttia ja $75 \%$ korkeintaan 6 minuutin mittaisia (Korhonen ym. 1999). Tämä on luonnollinen selitys sille, miksi lyhyen komponentin kestoksi saatiin vain muutama minuutti, mikä tarkoittaa samalla sitä, että lyhyt komponentti kuvaa pääasiassa toiminnon kestoa. Pitkä komponentti saattaa kuvata eläimen henkistä tilaa. Eli jos eläin on stressaantunut, se toistaa stereotyyppistä käyttäytymistä useamman kerran seuraavien 20-40 minuutin aikana. Pitkän komponentin kesto oli lepäämisessä selvästi pitempi kuin muissa muuttujissa. Harri ym. (1999) havaitsi, että hopeaketuilla lepojakso kestään keskimäärin 17-66 minuuttia ( $\mathrm{SD}=22-68)$ riippu- 
en vuodenajasta ja lattiamateriaalista. Koska raportoitu keskihajonta on suuri verrattuna keskiarvoon, niin lepojaksojen keston jakauman täytyy olla erittäin vino, jolloin iso osa lepäämisjaksoista täytyy olla kestoltaan keskiarvoa lyhyempiä.

Taulukko 1. Kaksi komponenttia sisältävän eksponentiaalisen variogrammimallin parametrien estimaatit neljälle toiminnolle kolmena eri vuorokaudenaikana.

\begin{tabular}{|c|c|c|c|c|c|}
\hline \multirow{3}{*}{ Muuttuja } & \multirow{3}{*}{ Vuorokaudenaika } & \multicolumn{4}{|c|}{ Komponentit } \\
\hline & & \multicolumn{2}{|c|}{ Lyhyt } & \multicolumn{2}{|c|}{ Pitkä } \\
\hline & & Range & Sill & Range & Sill \\
\hline \multirow[t]{3}{*}{ Lepääminen } & $0: 00-8: 00$ & 4.6 & 0.071 & 60 & 0.146 \\
\hline & $8: 00-16: 00$ & 4.2 & 0.026 & 69 & 0.090 \\
\hline & $16: 00-24: 00$ & 3.8 & 0.037 & 68 & 0.106 \\
\hline \multirow[t]{3}{*}{ Liikkuminen } & $0: 00-8: 00$ & 1.5 & 0.362 & 41 & 0.103 \\
\hline & $8: 00-16: 00$ & 1.5 & 0.384 & 32 & 0.072 \\
\hline & $16: 00-24: 00$ & 1.2 & 0.394 & 38 & 0.078 \\
\hline \multirow[t]{3}{*}{ Stereotypiat } & 0:00-8:00 & 1.8 & 0.422 & 28 & 0.074 \\
\hline & $8: 00-16: 00$ & 2.2 & 0.403 & 28 & 0.081 \\
\hline & $16: 00-24: 00$ & 2.4 & 0.416 & 23 & 0.075 \\
\hline \multirow[t]{3}{*}{ Itsensä raapiminen } & $0: 00-8: 00$ & 2.3 & 0.340 & 22 & 0.138 \\
\hline & $8: 00-16: 00$ & 1.8 & 0.415 & 26 & 0.066 \\
\hline & $16: 00-24: 00$ & 2.0 & 0.375 & 27 & 0.102 \\
\hline
\end{tabular}

\section{Optimaalinen otantatiheys}

Ensimmäisestä erotuksen keskivirheestä, $\mathrm{SED}_{1}$, ei löytynyt käytännössä merkittäviä eroja. Sitä vastoin $\mathrm{SED}_{2}$ ja $\mathrm{SED}_{3}$ sisälsivät useita merkittäviä eroja. $\mathrm{SED}_{2}$-arvoa voitiin laskea 10-20 \% kontrollin arvosta lisäämättä havaintojen lukumäärää harventamalla otantatiheyttä yhdestä minuutista 10-12 minuuttiin ja samanaikaisesti pidentämällä kuvauksen kestoa yhdestä vuorokaudesta kolmeen. Tätä suurempien muutosten aikaansaaminen onnistui vain lisäämällä havaintojen lukumäärää huomattavasti kontrollimenetelmästä pitämällä otantatiheyttä 2-4 minuutissa ja pidentämällä kuvauksen kesto 3-5 vuorokauteen. Näin saavutettu etu on tehtävään työmäärään suhteutettuna pieni, sillä vain stereotypioissa oli havaittavissa yli $10 \%$ :n hyötyä. Näin ollen 12 minuutin otantatiheys on optimaalinen aina kun kuvauspäiviä voidaan toteuttaa ainakin kolme. Mikäli kuvauspäiviä on vain yksi, niin otantatiheyttä ei kannata lyhentää alle neljään minuuttiin, sillä siitä saatava hyöty on olematon eikä sitä voitu aina edes havaita. $\mathrm{SED}_{3}$-arvon tulokset olivat samankaltaiset kuin $\mathrm{SED}_{2}$ :lla, joskin vaikutukset olivat jopa kaksinkertaisia etenkin stereotypioissa.

Otantamenetelmää on kritisoitu siitä, että sen avulla ei voida tutkia erilaisten käsittelyjen vaikutusta yksittäisten toimintajaksojen keskimääräiseen kestoon (Altmann 1974). Jos ainoa ero kahden tutkittavan käsittelyn välillä on keskimääräisessä jakson pituudessa, niin otantamenetelmä on väärä menetelmä eron havaitsemiseen. Kirjallisuudessa on ehdotettu muutamaa tapaa käytettäväksi asian korjaamiseksi (Ary ja Suen 1983; Quera 1990). Nyt tehdyn tutkimuksen perusteella voidaan perustellusti olettaa, että kaksi komponenttia sisältävän eksponentiaalisen mallin parametrit ovat sidoksissa toiminnon pituuteen. Näin ollen käsittelyjen välisiä eroja käyttäytymisjaksojen kestoissa on mahdollista tutkia epäsuoraan vertailemalla eri käsittelyjen tuottamaa variogrammia. Tämä edellyttää, että variogrammi voidaan mallittaa samanaikaisesti kaikille kokeessa mukana olleille käsittelyille ja eläimille. Tähän tarvitaan tilastollista mallia, jossa on sekä kiinteitä että satunnaisia vaikutuksia. Aika uusi SAS-proceduuri, NLMIXED (SAS 1999), sovittaa tällaisia malleja. Menetelmä sisältää vielä huomattavia rajoituksia (Pinheiro ja Bates 1995), mutta voi kuitenkin avata uusia mahdollisuuksia eläinten käyttäytymistutkimuksissa jo nyt tai lähitulevaisuudessa.

Tässä tutkimuksessa keskityttiin systemaattiseen otantaan, mutta myös muita otanta-asetelmia on mahdollista käyttää. Jos otanta ei ole systemaattinen, niin silloin otantaan tulee mukaan paljon aikapisteitä, joiden välinen etäisyys on niin lyhyt, että havainnot ovat voimakkaasti korreloituneita. Näin ollen systemaattinen otanta tulee olemaan aina tehokkain.

Optimaalisen otantatiheyden havaittiin vaihtelevan käyttäytymistoiminnolta toiselle. Teoriassa tehokkaimmassa tavassa otantatiheys on sellainen, että peräkkäiset havainnot eivät ole korreloituneita, sillä korreloituneet havainnot sisältävät vähemmän informaatiota kuin korreloimattomat. Bernstein 
(1991) on osoittanut, ettei täydellinen riippumattomuus ole tarpeellinen, mikä on sopusoinnussa nyt saatujen tulosten kanssa. Saadut tulokset ovat sopusoinnussa myös Mitlöhner ym. (2001) tulosten kanssa, sillä hän havaitsi käyttökelpoisen otantatiheyden olevan 10-15 minuuttia.

Saadut tulosten voidaan soveltaa suoraan käytäntöön vain sinikettututkimuksissa. Kirjallisuudesta löytyy paljon tutkimuksia useilla lajeilla, joissa otantatiheytenä on käytetty 1-3 minuuttia. Näistä aineistoista pystytään helposti variogrammin avulla arvioimaan käyttökelpoinen otantatiheys, mikä täytyy tuntea, mikäli uudet tutkimukset halutaan tehdä kustannustehokkaasti.

\section{Johtopäätökset}

Variogrammi on hyvä työkalu myös eläinten käyttäytymistutkimuksessa. Variogrammin avulla käyttäytymisestä voitiin tunnistaa kaksi komponenttia. Eläinten käyttäytymistutkimuksissa käytetään usein liian tiheää otantaa, jolloin joudutaan tekemään paljon turhaa työtä. Optimaalinen otantatiheys on 1015 minuuttia 3-5 vuorokautta kestäneissä kuvauksissa ja 4-6 minuuttia kun kuvaus kestää vuorokauden.

\section{Kirjallisuus}

Altmann, J. 1974. Observational study of behaviour: sampling method. Behaviour, 49: 227-265.

Andersen I.L, Knut E.B. \& Kristiansen A.L. 1999. The influence of different feeding arrangements and food type on competition at feeding in pregnant sows. Applied Animal Behaviour Science 65: 91-104.

Ary, D. \& Suen, H.K. 1983. The use of momentary time sampling to access both frequency and duration of behaviour. Journal of Behavioural Assessment, 5: 143-150.

Bernstein I.S. 1991. An empirical comparison of focal and ad libitum scoring with commentary on instantaneous scans, all occurance and one-zero techniques. Animal Behaviour 42: 721-728.

Diggle, P. 1990. Time series: a biostatistical introduction. Oxford University Press, Oxford.

Diggle, P, Liang, K., \& Zeger, S. 1994. Analysis of Longitudinal Data. Oxford Science Publications. 253 s.

Engel J. 1996. Choosing an appropriate sample interval for instantaneous sampling. Behavioural Processes 38 : 11-17.

Gumperetz, M.L. \& Browne, C. 1993. Repeated measures in randomized block and split-splot experiments. Canadian Journal of Forest Research, Volume 23: 625-639.

Harri, M., Mononen, J., \& Sepponen, J. 1999. Preferences of farmed silver foxes (Vulpes vulpes) for four different floor types. Canadian Journal of Animal Science 79: 1-5.

Jauhiainen, L., \& Korhonen, H.T. 2003. Autocorrelation of video-recorded observations in animal behaviour studies. In: Oiva Niemeläinen and Mari Topi-Hulmi (eds.). Proceedings of the NJF's 22nd congress 'Nordic Agriculture in Global Perspective', July 1-4, 2003, Turku, Finland. Jokioinen: MTT Agrifood Research Finland, NJF. [s. 9].

Lay C.D., Buchanan H.S. \& Haussmann M.F. 1999. A note on simulating the 'observer effect' using constant photoperiod on nursery pigs. Applied Animal Behaviour Science 63: 301-309.

Lehner, P.N. 1996. Handbook of ethological methods. $2^{\text {nd }}$ edition, Cambridge University press, London, UK, $472 \mathrm{~s}$.

Korhonen, H.T., Jauhiainen, L., \& Niemelä, P. 1999. Effect of enlarged cage space and access to earthen floor on locomotor and digging activity of blue foxes. Agricultural and food science in Finland, 8: 253-263.

Korhonen, H.T., Jauhiainen, L., \& Niemelä, P. 2001. Effect of space allowance and earthen flooring on behaviour of farmed blue foxes. Acta ethologica, 4: 11-21.

Lehner, P.N. 1996. Handbook of ethological methods. $2^{\text {nd }}$ edition, Cambridge University press, London, UK. $472 \mathrm{~s}$.

Martin, P. \& Bateson, P. 1986. Measuring behaviour: an introductory guide. Cambridge University Press, London, UK. $200 \mathrm{~s}$.

Mitlöhner, F.M., Morrow-Tesch, J. L., Wilson, S.C., Dailey, J.W. \& McGlone, J.J. 2001. Behavioral sampling techniques for feedlot cattle. J. Anim. Sci.: 79:1189-1192.

Pannatier, Y. 1996. VARIOWIN: Software for Spatial Data Analysis in 2D, Springer-Verlag, New York, NY. $91 \mathrm{~s}$.

Pinheiro, J.C. \& Bates, D.M. 1995. Approximations to the log-likelihood function in the nonlinear mixed effects model. Journal of Computational and Graphical Statistics, 4: 12-35.

Quera, V. 1990. A generalized technique to estimate frequency and duration in time sampling. Behavioral Assessment, 12: 409-424.

SAS 1999. SAS/STAT User's Guide, Version 8, Cary, NC: SAS Institute Inc. 3809 s.

Wolfinger, R. 1996. Heterogeneous Variance-Covariance Structures for Repeated Measures. Journal of Agricultural, Biological, and Environmental Statistics, Volume 1, Number 2: 205-230. 